\title{
TIMEROSAL Y VACUNACIÓN OBLIGATORIA
}

\author{
THIOMERSAL AND COMPULSORY VACCINATION
}

En lo técnico, el asunto del timerosal está resuelto: es insoluble. Planteada la sugerencia o presentada una evidencia científica, sólida o frágil, de su toxicidad, no hay modo de refutarla aun cuando la investigación científica y los expertos se inclinen, mayoritariamente, por señalar que la relación entre timerosal y autismo es inexistente, lo cual es imposible de demostrar, porque la comprobación de un riesgo nulo nunca puede ser definitiva. Se recurre, en consecuencia, al llamado principio de precaución que sirve a unos para insistir que se previenen riesgos, improbables pero no descartables, eliminando el timerosal; otros, temiendo que al no aplicar una vacuna demostradamente eficaz, se corra el riesgo de rebrotes de enfermedades exitosamente anuladas. El argumento de la precaución es manipulable, como quedó demostrado en la errónea y deletérea política precautoria de la OMS frente a la supuesta pandemia H1N1 de 2009-2010, por lo cual las políticas públicas no deben descansar en tal argumento.

El problema es otro: timerosal o no, ¿es democráticamente legítima una política de vacunación obligatoria? A lo largo de la historia, así como en muchas sociedades actuales, la opinión pública reclama el derecho de elegir acaso se inmunizarán, ellos y sus dependientes. El tema oscila entre una política paternalista que impone aquella estrategia utilitarista que minimiza riesgos, confiando en reducir la carga poblacional de enfermedad mediante inmunización activa, y la actitud liberal que deja el cálculo utilitarista de riesgos a criterio de los individuos. En 'la aventura de la vacunación', como relata la historiadora de la medicina A-M. Moulin, se produce la brecha que en forma perenne complica a la salud pública: la brecha entre bien colectivo y autonomía individual.

Desde esa perspectiva, la política de nuestro país es de una incoherencia

Miguel Kottow

Escuela de Salud Pública Facultad de Medicina Universidad de Chile mhkottow@gmail.com alarmante. La privatización de servicios sociales carga al ciudadano con la responsabilidad de contratar con cargo a su bolsillo aquello que el Estado se compromete constitucionalmente a proporcionar: salud, educación, protección social, ingreso mínimo. A pesar de esta neo-liberalización individualista, el Estado nos sorprende con obligaciones y prohibiciones, de 
las cuales el debate sobre vacunas es solo un caso entre varios ejemplos: desconocimiento de la voluntad autónoma en la esfera privada -reproducción, orientación sexual, proceso de muerte. Este autoritarismo ni siquiera tiene la justificación de servir al bien común, pues impone posturas doctrinarias en una sociedad laica y plural.

Los problemas técnicos - ¿es tóxico el timerosal?, ¿es abortivo el levonorgestrel?, y los dilemas éticos: ¿acaso y cómo es limitable la autonomía de las personas?, ¿es aceptable que una sociedad con un índice Gini superior a 0.5 imponga a sus ciudadanos un gasto de bolsillo en salud del $40 \%$ ? - no son resorte de políticos mal informados, que dicen representar a sus electores pero no averiguan lo que sus representados quieren.

Diversos conflictos sociales estallarán en tiempos próximos. La vacunación obligatoria es solo pensable bajo dos condiciones: la amenaza real de una enfermedad grave y la existencia de una inmunización activa eficaz y escasamente tóxica. Desde la erradicación de la viruela, estas condiciones no se han vuelto a presentar, de manera que es de esperar de las políticas sanitarias que resuelvan la incongruencia en que vivimos: un Estado que descarga sus deberes en los individuos al mismo tiempo que dictamina biopolíticas intrusas en la vida privada del ciudadano. 